\title{
Laparoscopic Fundoplication for the Surgical Management of Gastroesophageal Reflux Disease in Children
}

\author{
Charlene Dekonenko ${ }^{1}$ George W. Holcomb III \\ ${ }^{1}$ Department of Surgery, Children's Mercy Hospital, Kansas City, \\ Missouri, United States \\ Eur J Pediatr Surg 2020;30:150-155. \\ Address for correspondence Charlene Dekonenko, MD, Department \\ of Surgery, Children's Mercy Hospital, 2401 Gillham Road, Kansas \\ City, Missouri 64108, United States (e-mail: cdekonenko@cmh.edu).
}

\begin{abstract}
Gastroesophageal reflux (GER) is common in infants generally resolving in early childhood. However, gastroesophageal reflux disease (GERD) is diagnosed when persistent troublesome symptoms and/or complications of GER develop. These

Keywords

- fundoplication

- gastroesophageal reflux

- gastroesophageal reflux disease symptoms and complications can significantly affect the quality of life, thus requiring medical or surgical treatment. Medical management is typically trialed, but operative treatment is indicated with severe symptoms such as aspiration pneumonia, apneic episodes, bradycardia, apparent life-threatening events, severe vomiting, failure to thrive, esophagitis, stricture, and failed medical therapy. We review the recent literature on the indications and outcomes for laparoscopic fundoplication in the

- laparoscopic management of pediatric GERD.
\end{abstract}

\section{Introduction}

Gastroesophageal reflux (GER) is the involuntary retrograde passage of gastric contents into the esophagus with or without regurgitation or vomiting. It is common in infancy and is thought to be the result of transient lower esophageal relaxations (TLESRs) which occur independent of swallowing. Gastroesophageal reflux disease (GERD) is diagnosed when persistent troublesome symptoms and/or complications of GER develop and affect quality of life (QOL). ${ }^{1}$ These include failure to grow appropriately (failure to thrive [FTT]), respiratory complications, esophagitis, feeding or sleeping problems, chronic respiratory disorders, apnea, and apparent life-threatening events (ALTEs), and require medical and/ or surgical treatment. Complications of GERD develop due to failure of the normal physiologic barriers that prevent gastric contents from entering the esophagus, that limit esophageal injury by the refluxate, or that help clear the refluxate from the esophagus. A short lower esophageal sphincter (LES) length, abnormal smooth muscle function, increased TLESRs, malposition of the LES in the chest, and ineffective esoph- ageal clearance can contribute individually or collectively to the development of GERD.

\section{Diagnostic Evaluation}

There are low levels of evidence for the accuracy of diagnostic tests for evaluating GERD in children. ${ }^{2}$ However, in some patients, an upper gastrointestinal (UGI) contrast study and/or esophagogastroduodenoscopy is performed to rule out other diagnoses if the clinical picture is unclear. ${ }^{3}$ While combined multichannel intraluminal impedance (MII) and $\mathrm{pH}$ measurements are sensitive for the evaluation of GERD, ${ }^{4-6}$ its limitations include a weak association between acid exposure and the occurrence or severity of symptoms. ${ }^{3,7}$ Therefore, the diagnosis of GERD is largely clinical, particularly in infants, via a thorough history and physical exam with determination of age of symptom onset, pattern of symptoms, feeding and dietary history, family history, possible environmental triggers, growth trajectory, and prior interventions. $^{3}$ received

January 6, 2020

accepted

January 7, 2020

published online

March 4, 2020 (c) 2020 Georg Thieme Verlag KG Stuttgart · New York
DOI https://doi.org/ 10.1055/s-0040-1702139. ISSN 0939-7248. 
At our institution, over the past 5 years, we have moved away from preoperative imaging studies unless the information might be helpful in planning or managing the patient's operative care. ${ }^{8}$ As a general statement, our current practice is to manage most patients based on their clinical symptoms, both for medical management as well as operative therapy. Preoperative testing is reserved for patients with an unclear history and symptom complex as other disease processes can mimic symptoms of GERD such as hypertrophic pyloric stenosis, tracheoesophageal fistula, achalasia, intussusception, or other intestinal obstructive diseases such as Hirschsprung's disease, and should be considered prior to fundoplication. ${ }^{3}$

\section{Operative Management}

Operative indications for GERD include recurrent aspiration pneumonia, apneic episodes, bradycardia, ALTEs, bronchopulmonary dysplasia, severe vomiting, FTT, esophagitis, stricture, and failed medical therapy. ${ }^{9}$ In some circumstances, it may be best to proceed with fundoplication without a trial of medical therapy, such as with a patient in an intensive care unit with underlying respiratory disease who requires gastrostomy, or the neurologically impaired (NI) patient who needs gastrostomy and there is concern for aspiration from GERD. The latter scenario is common in infants and children, and the decision for fundoplication at the time of gastrostomy should be individualized. Another scenario is the infant with known GER presenting with an ALTE, and no other etiology is identified. Initial treatment with fundoplication should be considered in this case. In our own institutional review of 81 infants presenting with ALTE, symptoms resolved in all patients following fundoplication with a median follow-up of almost 4.8 years. $^{10}$ Interestingly, $96.3 \%$ of these patients had been previously treated with antireflux medication and $87.7 \%$ were taking antireflux medications at the time of their ALTE. Therefore, medical management may not be effective in these patients.

Initial operative therapy is also recommended in patients with Barrett's esophagus and/or esophageal stricture. The changes of Barrett's esophagus will usually resolve in adolescents following fundoplication; however, lifelong endoscopic surveillance is still required. With an esophageal stricture, esophageal dilation can be performed at the time of fundopli-
Table 1 Recommended bougie size for esophageal calibration in patients weighing $<15 \mathrm{~kg}$

\begin{tabular}{|l|l|}
\hline Weight $(\mathrm{kg})$ & Bougie size \\
\hline $2.5-4.0$ & $20-24$ \\
\hline $4.0-5.5$ & $24-28$ \\
\hline $5.5-7.0$ & $28-32$ \\
\hline $7.0-8.5$ & $32-34$ \\
\hline $8.5-10.0$ & $34-36$ \\
\hline $10.0-15.0$ & $36-40$ \\
\hline
\end{tabular}

Source: Holcomb GW III. ${ }^{41}$

cation, but subsequent dilations may still be needed in severe cases. Finally, children with a known hiatal hernia and symptomatic GER are unlikely to respond to medical management, so initial treatment with fundoplication is also warranted in these patients.

At our institution, we have standardized our technique. ${ }^{11-17}$ We perform the fundoplication with minimal mobilization of the esophagus to help reduce postoperative transmigration of the fundoplication wrap (-Fig. 1). In addition, a useful tool for determining the appropriate bougie size for neonates weighing less than $15 \mathrm{~kg}$ has been developed, validated, and used for more than 15 years ( $>$ Table 1 ). ${ }^{11}$ The fundoplication is then performed using a standard Nissen technique.

\section{Outcomes}

Our group has studied outcomes of patients following laparoscopic fundoplication for the past 20years. ${ }^{10-14,17-20}$ In an attempt to reduce the risk of transmigration, we modified our technique to limit esophageal mobilization by keeping the phrenoesophageal membrane intact, and placing sutures between the esophagus and crura, eliminating this space (-Fig. 1). As a result of these modifications, the incidence of transmigration was reduced to $5 \% .{ }^{18}$ This was confirmed in a multicenter prospective randomized trial showing an $8 \%$ transmigration rate in the minimal dissection group compared with a $30 \%$ rate in the extensive dissection group $(p=0.002)$ (- Table 2). Additionally, reoperation rates were higher in the
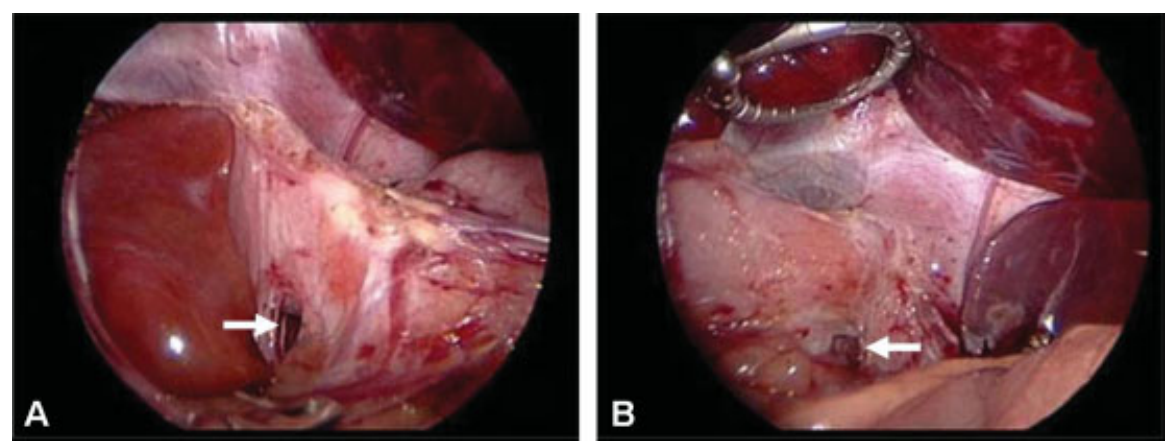

Fig. 1 If an adequate length of intra-abdominal esophagus is present, then as little dissection as possible is performed to help prevent migration of the fundoplication wrap through an enlarged esophageal hiatus. The phrenoesophageal ligament is kept intact on both the patient's (A) right side and (B) left side of the esophagus. Note creation of the retroesophageal window has been initiated (arrows). (Adapted from Holcomb III. ${ }^{49}$ ) 
Table 2 Outcomes from 177 patients who were randomized to receive either minimal esophageal dissection/mobilization or extensive esophageal dissection/mobilization

\begin{tabular}{|l|l|l|l|}
\hline & $\begin{array}{l}\text { Extensive } \\
\text { esophageal } \\
\text { mobilization } \\
(\mathrm{N}=\mathbf{8 7})\end{array}$ & $\begin{array}{l}\text { Minimal } \\
\text { esophageal } \\
\text { mobilization } \\
(\mathrm{N}=\mathbf{9 0})\end{array}$ & $p$-Value \\
\hline $\begin{array}{l}\text { Postoperative wrap } \\
\text { transmigration (\%) }\end{array}$ & 30.0 & 7.8 & 0.002 \\
\hline $\begin{array}{l}\text { Need for redo } \\
\text { fundoplication (\%) }\end{array}$ & 18.4 & 3.3 & 0.006 \\
\hline
\end{tabular}

Source: Holcomb GW III. ${ }^{41}$

extensive dissection group compared with the minimal dissection group (18 vs. $3 \%, p=0.006$ ). We then followed up the patients from our center who participated in the trial. Postoperative wrap transmigration, identified by an UGI contrast study at 1 year, was found in $22.7 \%$ of those with extensive mobilization and $2.8 \%$ in those with minimal mobilization. ${ }^{13}$

In 2017, we reported our final prospective randomized trial investigating the utility of the four esophagocrural sutures used in the previous study. ${ }^{14}$ In 53 patients, four esophagocrural sutures were utilized and in 54 patients, esophagocrural sutures were not utilized. No wrap herniations occurred in either group 1 year postoperatively and there was no difference in reoperations $(p=1.0)$. Reflux symptoms and medications were not different at 1 month, 1 year, and final follow-up. Therefore, we no longer use esophagocrural sutures and employ minimal esophageal mobilization.

Laparoscopic fundoplication is safe and feasible even in children who have had a previous open operation. ${ }^{21}$ The laparoscopic approach has been associated with a lower incidence of retching, shorter length of stay, and less morbidity, but a higher cost and longer operative times. ${ }^{5,22-26}$ Some authors have also reported a higher rate of recurrence of GERD in the laparoscopic approach compared with the open approach. ${ }^{5,23,27}$ In the past 5 years, there has been one prospective randomized trial comparing recurrence of GERD in children for the two approaches. ${ }^{23}$ Eighty-seven children were randomized, and at a median follow-up of 4 years, more patients in the laparoscopic fundoplication (LF) group (37\%) experienced recurrence of GERD compared with the open fundoplication (OF) group (7\%). In another recent report, the authors evaluated the 4-year results following a randomized controlled trial comparing OF and LF in 31 children. The incidence of recurrent GERD was $12.5 \%$ in the OF group and $20 \%$ in the LF group ( $p=$ not significant), but nutritional status and QOL improved in both groups. However, LF was associated with a reduced incidence of retching $(p=0.01) .^{22}$

Several recent studies have evaluated the need for fundoplication following gastrostomy. In one study of 684 patients undergoing gastrostomy alone, of which 124 were open, 282 laparoscopic, and 278 percutaneous endoscopic gastrostomy (PEG), subsequent fundoplication was needed in 62 patients (9.1\%) at a mean of 20.7 months following gastrostomy. Cerebral palsy and anoxic brain injury were independent predictors for the need for subsequent fundoplication. Interestingly, gastrostomy performed laparoscopically had a negative correlation with the subsequent need for fundoplication. ${ }^{27}$ In a smaller study, $17 \%$ of NI patients who underwent gastrostomy alone needed a subsequent fundoplication. ${ }^{28}$

In another study, the authors looked at the need for fundoplication in patients undergoing open gastrostomy (OG) compared with PEG. A higher percentage of patients who underwent OG (54\%) needed fundoplication compared with $27 \%$ who underwent PEG. ${ }^{29}$ In an interesting study, 26 NI patients who underwent laparoscopic gastrostomy were evaluated with $\mathrm{pH}-\mathrm{MII}$ monitoring and gastric emptying studies, to see if their GER improved or worsened postoperatively. The authors found that the laparoscopic gastrostomy reduced GER in NI patients by improving gastric emptying. ${ }^{30}$

Finally, no superiority in control of reflux symptoms has been shown between partial and complete wraps. ${ }^{31}$ Although effectiveness is comparable, a complete wrap may lead to more postoperative dysphagia that may require endoscopic dilation. ${ }^{7}$ The use of the anterior hemifundoplication, as opposed to the Nissen fundoplication, has been recently evaluated. ${ }^{32,33}$ The authors evaluated QOL from the parents of both neurologically healthy and NI children following anterior hemifundoplication. In both groups, there was a significant improvement in QOL for the children and their parents along with improvement in the patients' reflux symptoms. Most surgeons prefer the Nissen fundoplication as it is a more straightforward technique and easier to perform laparoscopically than the Thal fundoplication, which is the second most commonly utilized technique in infants and children. In a recent prospective randomized trial, the laparoscopic Nissen fundoplication was successful in $99 \%$ of the patients, with only one patient requiring a redo procedure due to "loosening" of the wrap. ${ }^{14}$

In a recent report evaluating parental satisfaction following fundoplication with a median follow-up of 7.3 years, a high percentage of parents reported an improvement in gastrointestinal reflux-related symptoms and a high level of satisfaction following fundoplication. ${ }^{34}$

In a prospective study comparing NI patients with non-NI patients undergoing Nissen fundoplication, hospital stay was longer for NI children compared with non-NI children (9 days [range: $4-57$ ] vs. 4 days [range: $2-16$ ], $p<0.001) .{ }^{34}$ However, more than $90 \%$ of the parents in both groups reported that the fundoplication had improved the child's overall condition. Twelve NI and seven non-NI patients had recurrence of GERD $(p=0.31)$. Therefore, the authors concluded that early complications, recurrence, and parental satisfaction after fundoplication did not differ between NI and non-NI patients. Though overall QOL is reported to be lower in NI patients compared with non-NI patients following fundoplication, there is still a significant improvement in QOL after fundoplication compared with before fundoplication in NI patients. ${ }^{35}$

\section{Redo Fundoplication}

Complications of fundoplication include dysphagia from a wrap that is too tight, retching, gas bloat syndrome, 
breakdown of the wrap, hiatal herniation, slipped wrap, and recurrence of reflux. ${ }^{18,23,36,37}$ Recurrence of GERD is $<10$ to $20 \%{ }^{2}$ Risk factors for recurrence include younger age at the time of surgery, presence of a preoperative hiatal hernia, postoperative retching, and the need for postoperative esophageal dilations. ${ }^{18,38}$ Some patients with underlying disorders, such as esophageal atresia, are at increased risk of wrap failure with $15 \%$ failing long term, and 18 to $32 \%$ of redo fundoplications also fail in this patient group. ${ }^{38,39}$ As previously mentioned, studies have shown that minimal esophageal mobilization in laparoscopic Nissen fundoplication decreases postoperative wrap transmigration and the need for a redo fundoplication. ${ }^{12,13,16}$ A radionucleotide scan can be done prior to reoperation to assess for delayed gastric emptying, in which case a pyloroplasty may be considered if the patient needs a redo fundoplication. ${ }^{40}$

Our group has focused on preventing the need for a second operation. ${ }^{38,39,41,42}$ In addition, we have also described the use of biosynthetic mesh to enhance hiatal repair at the time of a redo Nissen fundoplication. ${ }^{43}$ In 2016 , we performed a two-center review of all our patients who underwent a redo operation following an initial laparoscopic Nissen fundoplication. ${ }^{38}$ Between 2000 and 2013, 796 patients underwent an antireflux operation and 82 patients (10\%) required a reoperation. Interestingly, 15 of the 82 patients (18.3\%) required more than one reoperation. Of the 102 reoperations performed, 68 were done laparoscopically. When comparing patients requiring more than one reoperation with those requiring only a single reoperation, there was no difference in age, weight, use of mesh, or time to subsequent reoperation. However, when looking at patients operated on before 2009, prior to discovering that minimal esophageal mobilization leads to a reduced need for redo fundoplication, 70 patients $(13.7 \%)$ required at least one reoperation. This was in contrast to only 12 patients (4.2\%) who required a reoperation after 2009 when we modified our technique to minimize esophageal mobilization. Furthermore, the indications for reoperation also changed after 2009 as $78.5 \%$ of the patients undergoing a redo operation before 2009 were due to wrap transmigration, and only $33.3 \%$ underwent a redo operation due to wrap transmigration after $2009(p<0.01)$. Wrap disruption $(50 \%)$ as the cause for the need for a redo fundoplication was more common after 2009 versus before 2009 (5.7\%).

In a recent single surgeon series with 252 patients undergoing a laparoscopic redo fundoplication, 84 had undergone previous open fundoplication and 32 had multiple prior fundoplications. ${ }^{44}$ The average time to full feeds was 1.4 days and an average hospital length of stay was 1.6 days. The postoperative complication rate was $3.6 \%$ and the wrap failure rate was $6.2 \%$, with the most common cause due to transmigration of the wrap.

The exact mechanism whereby a fundoplication, especially using the Nissen technique, relieves/improves GER remains unclear. A recent article looked at $13 \mathrm{NI}$ patients between 8 months and 20 years of age, where impedance/ pH studies were performed before their laparoscopic Nissen fundoplication and 1 year after it. ${ }^{45}$ The authors found that the laparoscopic Nissen fundoplication prevented high-volume reflux, mainly acid reflux episodes, from reaching the proximal esophagus, thus improving the mucosal integrity up to the middle of the esophagus. There was a marked reduction in the number of total reflux episodes and the number of proximal reflux episodes following the laparoscopic Nissen fundoplication. Additionally, previous studies have shown that the Nissen fundoplication decreased the number and magnitude of the TLESRs. ${ }^{46,47}$ Finally, a previous study showed that the Nissen fundoplication disrupts the vagal input to the gastroesophageal junction, which may be another mechanism by which the Nissen fundoplication also reduces/prevents GER. ${ }^{48}$

Laparoscopic fundoplication has become the preferred technique for the surgical management of GERD. However, it is only through critical evaluation of one's experiences and the experiences of others that advances are made in improving our results for our patients. Patients have less discomfort, a shorter hospital length of stay, and a faster return to regular activities following the laparoscopic approach. However, the operative technique should be continuously evaluated with proper data collection and critical analysis in order to improve patient outcomes.

Conflict of Interest

None declared.

\section{References}

1 Davies I, Burman-Roy S, Murphy MS; Guideline Development Group. Gastro-oesophageal reflux disease in children: NICE guidance. BMJ 2015;350:g7703

2 Jancelewicz T, Lopez ME, Downard CD, et al. Surgical management of gastroesophageal reflux disease (GERD) in children: a systematic review. J Pediatr Surg 2017;52(08):1228-1238

3 Rosen R, Vandenplas Y, Singendonk M, et al. Pediatric Gastroesophageal Reflux Clinical Practice Guidelines: Joint Recommendations of the North American Society for Pediatric Gastroenterology, Hepatology, and Nutrition and the European Society for Pediatric Gastroenterology, Hepatology, and Nutrition. J Pediatr Gastroenterol Nutr 2018;66(03):516-554

4 Vandenplas Y, Rudolph CD, Di Lorenzo C, et al; North American Society for Pediatric Gastroenterology Hepatology and Nutrition; European Society for Pediatric Gastroenterology Hepatology and Nutrition. Pediatric gastroesophageal reflux clinical practice guidelines: joint recommendations of the North American Society for Pediatric Gastroenterology, Hepatology, and Nutrition (NASPGHAN) and the European Society for Pediatric Gastroenterology, Hepatology, and Nutrition (ESPGHAN). J Pediatr Gastroenterol Nutr 2009;49(04):498-547

5 Safe M, Cho J, Krishnan U. Combined multichannel intraluminal impedance and ph measurement in detecting gastroesophageal reflux disease in children. J Pediatr Gastroenterol Nutr 2016;63 (05):e98-e106

6 Mousa HM, Rosen R, Woodley FW, et al. Esophageal impedance monitoring for gastroesophageal reflux. J Pediatr Gastroenterol Nutr 2011;52(02):129-139

7 Wakeman DS, Wilson NA, Warner BW. Current status of surgical management of gastroesophageal reflux in children. Curr Opin Pediatr 2016;28(03):356-362

8 Fike FB, Pettiford JN, St Peter SD, Cocjin J, Laituri CA, Ostlie DJ. Utility of $\mathrm{pH} /$ multichannel intraluminal impedance probe in identifying operative patients in infants with gastroesophageal 
reflux disease. J Laparoendosc Adv Surg Tech A 2012;22(05): 518-520

9 Yoo BG, Yang HK, Lee YJ, Byun SY, Kim HY, Park JH. Fundoplication in neonates and infants with primary gastroesophageal reflux. Pediatr Gastroenterol Hepatol Nutr 2014;17(02):93-97

10 Valusek PA, St Peter SD, Tsao K, Spilde TL, Ostlie DJ, Holcomb GW III. The use of fundoplication for prevention of apparent lifethreatening events. J Pediatr Surg 2007;42(06):1022-1024

11 Ostlie DJ, Miller KA, Holcomb GW III. Effective Nissen fundoplication length and bougie diameter size in young children undergoing laparoscopic Nissen fundoplication. J Pediatr Surg 2002;37(12):1664-1666

12 St Peter SD, Barnhart DC, Ostlie DJ, et al. Minimal vs extensive esophageal mobilization during laparoscopic fundoplication: a prospective randomized trial. J Pediatr Surg 2011;46(01):163-168

13 Desai AA, Alemayehu H, Holcomb GW III, St Peter SD. Minimal vs. maximal esophageal dissection and mobilization during laparoscopic fundoplication: long-term follow-up from a prospective, randomized trial. J Pediatr Surg 2015;50(01):111-114

14 St. Peter SD, Poola A, Adibe O, et al. Are esophagocrural sutures necessary during a laparoscopic fundoplication: a prospective randomized trial. J Pediatr Surg 2018;53:25-29

15 Georgeson K, Owings E. Surgical and laparoscopic techniques for feeding tube placement. Gastrointest Endosc Clin N Am 1998;8 (03):581-592

16 Aprahamian CJ, Morgan TL, Harmon CM, Georgeson KE, Barnhart DC. U-stitch laparoscopic gastrostomy technique has a low rate of complications and allows primary button placement: experience with 461 pediatric procedures. J Laparoendosc Adv Surg Tech A 2006;16(06):643-649

17 Ostlie DJ, Miller KA, Woods RK, Holcomb GW III. Single cannula technique and robotic telescopic assistance in infants and children who require laparoscopic Nissen fundoplication. J Pediatr Surg 2003;38(01):111-115

18 St Peter SD, Valusek PA, Calkins CM, Shew SB, Ostlie DJ, Holcomb GW III. Use of esophagocrural sutures and minimal esophageal dissection reduces the incidence of postoperative transmigration of laparoscopic Nissen fundoplication wrap. J Pediatr Surg 2007; 42(01):25-29

19 Holcomb GW III. Gastroesophageal reflux in infants and children. In: Fischer JE, ed. Mastery of Surgery, 6th ed. Philadelphia: Lippincott Williams \& Wilkins; 2012:769-780

20 Ostlie DJ, St Peter SD, Snyder CL, Sharp RJ, Andrews WS, Holcomb GW III. A financial analysis of pediatric laparoscopic versus open fundoplication. J Laparoendosc Adv Surg Tech A 2007;17(04):493-496

21 Barsness KA, St Peter SD, Holcomb GW III, Ostlie DJ, Kane TD. Laparoscopic fundoplication after previous open abdominal operations in infants and children. J Laparoendosc Adv Surg Tech A 2009;19(Suppl 1):S47-S49

22 Pacilli M, Eaton S, McHoney M, et al. Four year follow-up of a randomised controlled trial comparing open and laparoscopic Nissen fundoplication in children. Arch Dis Child 2014;99(06): 516-521

23 Fyhn TJ, Knatten CK, Edwin B, et al. Randomized controlled trial of laparoscopic and open Nissen fundoplication in children. Ann Surg 2015;261(06):1061-1067

24 Leung L, Wong CW, Chung PH, Wong KK, Tam PK. Laparoscopic Nissen fundoplication for gastro-oesophageal reflux disease in infants. Pediatr Surg Int 2015;31(01):83-88

$25 \mathrm{Ru} \mathrm{W}$, Wu P, Feng S, Lai XH, Chen G. Laparoscopic versus open Nissen fundoplication in children: a systematic review and metaanalysis. J Pediatr Surg 2016;51(10):1731-1736

26 Zhang P, Tian J, Jing L, Wang Q, Tian J, Lun L. Laparoscopic vs. open Nissen's fundoplication for gastro-oesophageal reflux disease in children: a meta-analysis. Int J Surg 2016;34:10-16

27 Ponsky TA, Gasior AC, Parry J, et al. Need for subsequent fundoplication after gastrostomy based on patient characteristics. J Surg Res 2013;179(01):1-4
28 Viswanath N, Wong D, Channappa D, Kukkady A, Brown S, Samarakkody U. Is prophylactic fundoplication necessary in neurologically impaired children? Eur J Pediatr Surg 2010;20 (04):226-229

29 Lintula H, Juvonen P, Hämynen I, Heikkinen M, Eskelinen M. Severe gastro-oesophageal reflux necessitating fundoplication after percutaneous endoscopic and open gastrostomy in children. Langenbecks Arch Surg 2013;398(05):703-707

30 Kawahara H, Tazuke Y, Soh H, Yoneda A, Fukuzawa M. Does laparoscopy-aided gastrostomy placement improve or worsen gastroesophageal reflux in patients with neurological impairment? J Pediatr Surg 2014;49(12):1742-1745

31 Fasching G, Huber A, Uray E, Sorantin E, Lindbichler F, Mayr J. Gastroesophageal reflux and diaphragmatic motility after repair of congenital diaphragmatic hernia. Eur J Pediatr Surg 2000;10 (06):360-364

32 Engelmann C, Gritsa S, Gratz KF, Ure BM. Laparoscopic anterior hemifundoplication improves key symptoms without impact on GE in children with and children without neurodevelopmental delays. J Pediatr Gastroenterol Nutr 2010;51(04):437-442

33 Engelmann C, Gritsa S, Ure BM. Impact of laparoscopic anterior 270 degrees fundoplication on the quality of life and symptoms profile of neurodevelopmentally delayed versus neurologically unimpaired children and their parents. Surg Endosc 2010;24(06): 1287-1295

34 Heinrich M, Kain A, Bergmann F, von Schweinitz D. Parents reported reduced symptoms and improved satisfaction after fundoplication and their perceptions were an important outcome measure. Acta Paediatr 2017;106(01):168-173

35 Knatten CK, Kvello M, Fyhn TJ, et al. Nissen fundoplication in children with and without neurological impairment: a prospective cohort study. J Pediatr Surg 2016;51(07):1115-1121

36 Mauritz FA, Stellato RK, van Heurn LWE, et al. Laparoscopic antireflux surgery increases health-related quality of life in children with GERD. Surg Endosc 2017;31(08):31223129

37 Lin DC, Chun CL, Triadafilopoulos G. Evaluation and management of patients with symptoms after anti-reflux surgery. Dis Esophagus 2015;28(01):1-10

38 Baerg J, Thorpe D, Gasior A, Vannix R, Tagge E, St Peter S. Factors associated with mortality after Nissen fundoplication in children. Eur J Pediatr Surg 2015;25(03):277-283

39 Desai AA, Alemayehu H, Dalton BG, et al. Review of the experience with re-operation after laparoscopic Nissen fundoplication. J Laparoendosc Adv Surg Tech A 2016;26(02):140-143

40 Koivusalo AI, Pakarinen MP. Outcome of surgery for pediatric gastroesophageal reflux: clinical and endoscopic follow-up after 300 fundoplications in 279 consecutive patients. Scand J Surg 2018;107(01):68-75

41 Holcomb GW III. “Gastroesophageal reflux.”. In: Holcomb GW III, Murphy JP, St. Peter SD, eds. Holcomb and Ashcraft's Pediatric Surgery, 7th ed. St. Louis: Elsevier Inc.; 2020:460-477

42 Ostlie DJ, Holcomb GW III. Reiterative laparoscopic surgery for recurrent gastroesophageal reflux. Semin Pediatr Surg 2007;16 (04):252-258

43 St Peter SD, Ostlie DJ, Holcomb GW III. The use of biosynthetic mesh to enhance hiatal repair at the time of redo Nissen fundoplication. J Pediatr Surg 2007;42(07):1298-1301

44 Bansal S, Rothenberg SS. Evaluation of laparoscopic management of recurrent gastroesophageal reflux disease and hiatal hernia: long term results and evaluation of changing trends. J Pediatr Surg 2014;49(01):72-75

45 Fukahori S, Yagi M, Ishii S, et al. Laparoscopic Nissen fundoplication mainly reduces the volume of acid reflux and potentially improves mucosal integrity up to the middle esophagus in neurologically impaired children detected by esophageal combined pH-multichannel intraluminal impedance measurements. J Pediatr Surg 2016;51 (08):1283-1287 
46 Ireland AC, Holloway RH, Toouli J, Dent J. Mechanisms underlying the antireflux action of fundoplication. Gut 1993;34(03): 303-308

47 Straathof JW, Ringers J, Masclee AA. Prospective study of the effect of laparoscopic Nissen fundoplication on reflux mechanisms. Br J Surg 2001;88(11):1519-1524
48 Sarani B, Chan T, Wise R, Evans S. Nissen fundoplication has a vagolytic effect on the lower esophageal sphincter. Surg Endosc 2003;17(08):1206-1211

49 Holcomb III. Laparoscopic Nissen fundoplication. In: Holcomb GWIII, Georgeson KE, Rothenberg SS, eds. Atlas of Pediatric Laparoscopy and Thoracoscopy. Philadelphia: Elsevier; 2008:15-20 